\title{
Problems of training specialists for trade in the conditions of digitalization
}

\author{
Elena Korchagina ${ }^{1, *}$, Larisa Desfonteines ${ }^{1}$, and Natalia Strekalova ${ }^{2}$ \\ ${ }^{1}$ St. Petersburg Peter the Great Polytechnic University, St. Petersburg, Russian Federation \\ ${ }^{2}$ Herzen State Pedagogical University of Russia, St. Petersburg, Russia
}

\begin{abstract}
The article considers the problems of staff training for trade in connection with the main modern trends in the economy of developed countries. On the one hand, information processes are rapidly developing in all areas of economic activity. On the other hand, the labor market has undergone structural changes related to the aging of the population. For successful competition, modern retail chains require qualified specialists of secondary education and skilled workers with digital technology skills. At the same time, there are large number of older professionals work in the trade, who do not have skills of using of digital equipment and plan to improve their skills. In addition, modern Russian technical schools and colleges do not train special skills of working with digital equipment for trading. The article suggests ways to transform the training system for trade in accordance with the requirements of the digital environment.
\end{abstract}

\section{Introduction}

Information technologies are rapidly developing now all around the world. The digital equipment development has led to changes in the requirements of employers in the labor market. In the Russian Federation, digitalization has affected most Russian manufacturing enterprises. These changes also affected the organization of trade enterprises. In modern literature, various influences on the labor market are considered. The article by H. Afonso and D. Holland notes the impact of two trends in trade policy on the US labor market, both of them related to political decisions [1]. Despite the fact that political factors are crucial in the development of the labor market, a number of authors note the impact of technological processes, in particular, digitalization on changes in requirements for specialists and, as a result, the transformation of the labor market. The authors note that digital transformation and the resulting innovations have radically changed consumer expectations and behavior in the field of trade, putting huge pressure on traditional forms of trade, destroying numerous markets [2].

On the one hand, the positive impact is noted. The information technologies impact on the development of new forms of entrepreneurship. On the other hand, the impact of digital technologies and business process cooperation requires careful study and additional largescale research. UK labor market research conducted by N. Leea and St. Clarkeb in 2016

* Corresponding author: elena.korchagina@mail.ru 
focused on the impact of enterprise digitalization on job cuts for low-skilled and midskilled workers. The authors proved that the development of information technologies and the digital economy shows a positive effect: the development of innovations does not reduce jobs, but creates new work places. Every 10 new high-tech jobs create about 7 jobs in the service sector, 6 of which relate to unskilled workers. The number of jobs for middleskilled workers does not increase, but they can benefit from wage growth [3]. Digital technologies currently have a significant impact on the interaction of production and trade enterprises. G. E. Alessandro and M. G. Passiante propose the definition of the digital enterprise ecosystem by highlighting integrated perspectives of digital production and the digital environment [4]. Working in a digital environment requires employees who have information technology skills not only in high-skilled positions, but also in low-and medium-skilled jobs. Digital positions today are more in demand in the labor market. For example, according to a modern study, in 2022 , about $22 \%$ of new jobs in the global economy will be created due to digital technologies [5]. In the foreseeable future, the main focus will be on using the labor potential of employees with the necessary digital competencies. According to the results of the employers' survey, $73 \%$ of them currently experience serious problems when searching for qualified specialists with skills to work with digital technologies [6]. In addition to the lack of specialists who know digital technologies, the future division of labor between man and machine implies changes in educational technologies. The growing digitalization of the economy and advances in artificial intelligence do not allow the automation of non-standard tasks that require creativity and imagination, which are among the most unique human abilities. L. G. Hammershoj suggests that future education should combine creative competencies with digital ones [7]. A study of the German labor market in connection with the digitalization of the economy, conducted by K. Dengler and B. Matthes, presented the degree of future automation of professions. The authors showed that only certain tasks in a profession can be replaced. The study looked at 8,000 tasks that can be replaced by computers or computer-controlled machines. Assuming that only certain tasks can be replaced, the authors proved that only $15 \%$ of German employees are at risk. In addition, there is evidence of employment growth in the digital economy [8]. E. Otiţan, A. Burciu, D. Manea, and A. Ardelean analyzed the EU strategy in the era of the digital revolution with regard to the relationship between education, digital environment and labor market. The authors concluded that it is necessary to minimize the gap between supply and demand in the labor market for workers with developed digital competencies. They have emphasized the importance of updating the education system in the field of information technologies in order to meet the expectations of the growing and constantly changing digital environment [9].

Digitalization of retail is usually associated with a reduction in sales staff and increased independence of customers. However, it is necessary to look for new opportunities in mastering the skills of working with modern digital devices. The distribution of professional responsibilities between employees and digital equipment will transform the monotonous functions of the staff, speed up work processes and create additional working time for new tasks.

\section{Results and Discussion}

The strategy for the development of the information society in the Russian Federation, approved in 2017, defined the main directions for the development of the digital economy [Digital economy of Russian Federation, http://government.ru/media/files]. The goal of digital transformation of the industry is to increase the economic and production efficiency of Russian enterprises. The work of a modern enterprise in the conditions of digitalization 
is impossible without providing qualified personnel not only at the highest level of qualification, but also with technicians and workers who have the competence to repair and management of digital objects.

In Russian retail, digital technologies for automating business processes are actively used both in large retail chains and in small stores. Moreover, innovative technologies provide a new format of relations not only with business partners, but also with customers. Modern customers strive to save time, convenience and individual approach to service. Retail is developing a systematic approach to innovation that takes into account the interests of all participants. Currently, the main task of implementing information technologies in retail chains is to provide an individual approach to serving customers with different tastes and needs by reducing the service time and maximizing the achievement of the purchase goal. To perform these tasks, CRM systems are most often used, which allows retailers to maintain a customer base, receive requests from them, segment customers and their needs, and offer individual loyalty programs. ERP systems for retail provide interaction with suppliers, accounting for warehouse products, and analysis of demand and sales. Distribution of the load on the staff in retail chains also uses digital technologies. Workforce management system allows retailers to calculate the optimal number of employees depending on the production load in a particular enterprise, to create a staff work schedule taking into account vacations, as well as to analyze and predict the activity of the staff. The growth in the use of both ERP-systems and CRM-systems is stable. Moreover, the growth of CRM-systems is slightly ahead of the introduction of ERPsystems. This can be explained by the functionality of CRM systems, which can be used both in large retail chains and in small enterprises. In addition, the cost of CRM systems is more flexible and affordable for retailers $[10,11]$.

The analysis of digitalization of trade enterprises in the Russian Federation allows us to draw the following conclusions:

- a modern buyer prefers a variety of channels for purchasing goods [12];

- retail consistently uses software to manage sales and purchases, which greatly facilitates the work of staff, but also requires special qualifications;

- there has been an increase in the use of ERP systems and CRM systems for optimizing business processes in trade. The use of data from these information systems requires highly qualified personnel, responsibility and experience in the field of trade [13].

Information technologies in trade in the form of an integration platform allow retailers to choose the best communication channel and provide an individual approach to the consumer. The organization of retail space is provided by a digital system for designing the location of departments of a commercial enterprise. Geographic information systems for retail networks allow retailers to predict the location of new branches of the network, analyze the profitability of the enterprise, and determine the optimal system of sales channels for products.

Digital technologies of Russian trade are actively developing and provide an increase in the efficiency of trade enterprises. This does not exclude problems that are currently occurring or that may occur in the future. These include:

- small number of qualified personnel;

- lack of digital skills among older workers;

- small number of educational institutions that educate specialists for work in the conditions of trade sphere digitalization.

It is necessary to upgrade the system of training middle-level specialists and skilled workers for preventing problems with the qualified personnel education for trade in the context of the rapid expansion of information technologies. The rapid growth and development of digital technologies is combined with demographic changes in the structure of the labor market associated with the aging of the working-age population. The skilled 
workers and technicians with special secondary education are people over the age of 50 in most Russian enterprises. The labor market does not offer an adequate number of skilled workers under 40 years of age and specialists with the special secondary education. The main staff of the enterprises is in the age group from 41 to 50 years. Employees under 25 are represented as unskilled workers. Most likely, these are migrants who came to the Russian Federation from Central Asia. The share of young people among skilled workers is low. Figure 1 shows data for the age groups of unskilled workers, skilled workers, managers, and engineers.

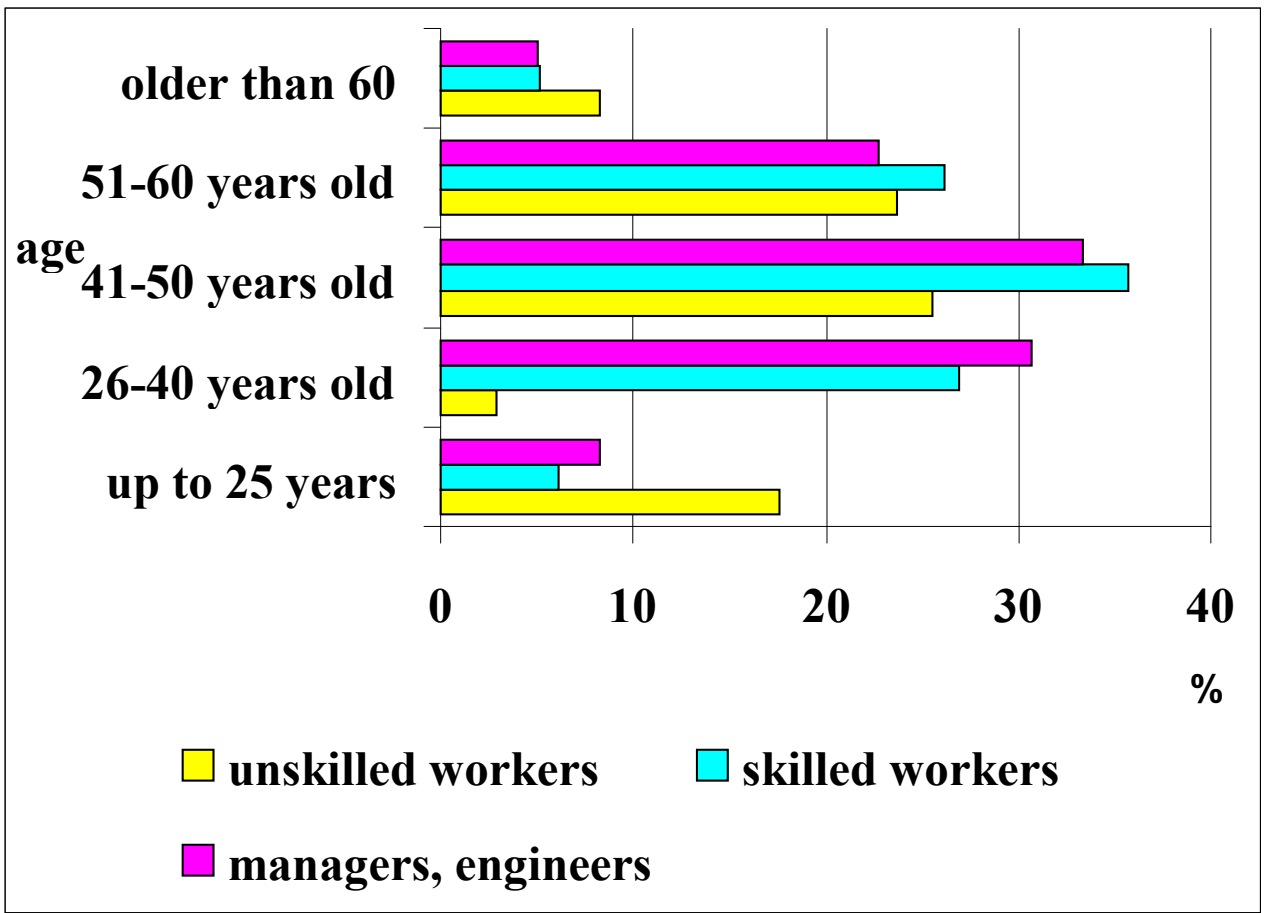

Fig. 1. Age structure of employees of industrial enterprises of the Russian Federation (Source: Rosstat, http://www.gks.ru).

Trade enterprises, as well as industrial enterprises in Russia, have difficulties in hiring qualified workers. If the number of unskilled workers is replenished by migrants, it is more difficult to solve the problem of founding of skilled workers. The main reasons are:

- shortage of young people with secondary education who have sufficient qualifications in information technology;

- shortage of professional training in secondary schools related to the use of information technologies in commercial enterprises;

- small amount of graduates of professional secondary educational institutions in popular areas of training for trade enterprises.

Education establishment do not train the necessary number of skilled workers and specialists of secondary education, which are in demand on the labor market by employers. Due to the lack of representation in the labor market of young qualified personnel of secondary education and skilled workers, competition between enterprises within the industry to attract energetic and creative workers has increased. If a few decades ago, the "recruiting" of professionals concerned only the top personnel, then in recent years this trend has been related to qualified middle-level specialists and skilled workers. The desire 
to provide a competitive advantage is connected with the improvement of human capital by "recruiting" already working specialists from other enterprises. The most popular is the generation of young people born after the 80 -s, who used information technologies at a good level. This age cohort is seen as a successful investment in human capital and the future of the enterprise associated with the digital transformation of all business processes. Figure 2 shows data on the composition of specialists in the field of information technology. Totally dominated by highly qualified specialists who graduate from higher education institutions. At the same time, the introduction and use of digital technologies in trade requires specialists of average qualification: electronics technicians, equipment installers, system administrators and qualified workers who provide repair and adjustment of equipment. There are very few such specialists. Secondary educational institutions (technical schools and colleges) do not train specialists to work with CRM systems, ERP systems, and digital platforms that are used in retail chains.

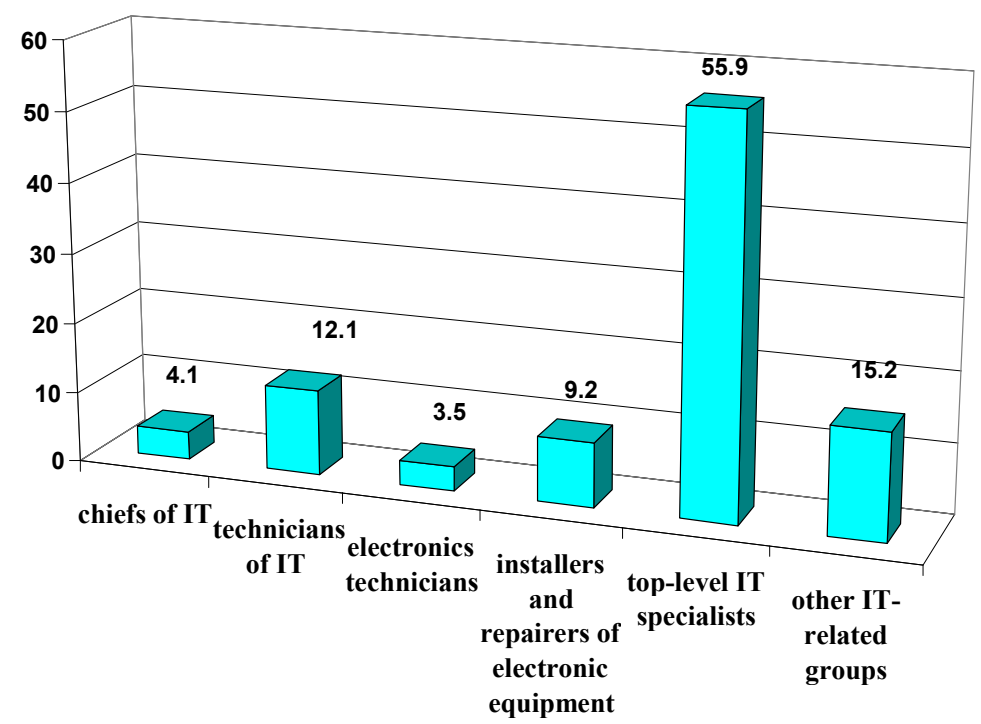

Fig. 2. Composition of ICT specialists in the Russian Federation, 2018 (Source: Rosstat, http://www.gks.ru).

Professional skills in the digital environment are becoming the main requirements for employers in all areas of the economy [14]. There is a difference in the skills of working with information processes and digital equipment between the younger generation of employees and the older generation. While young employees are focused on using the latest digital technologies, the older generation is confused and frustrated by the necessity of using of digital technologies. Figure 3 shows the reasons, according to survey of managers of trade enterprises, that interrupt the development of digital technologies to improve the efficiency of customer service and business processes in the trade sphere. 


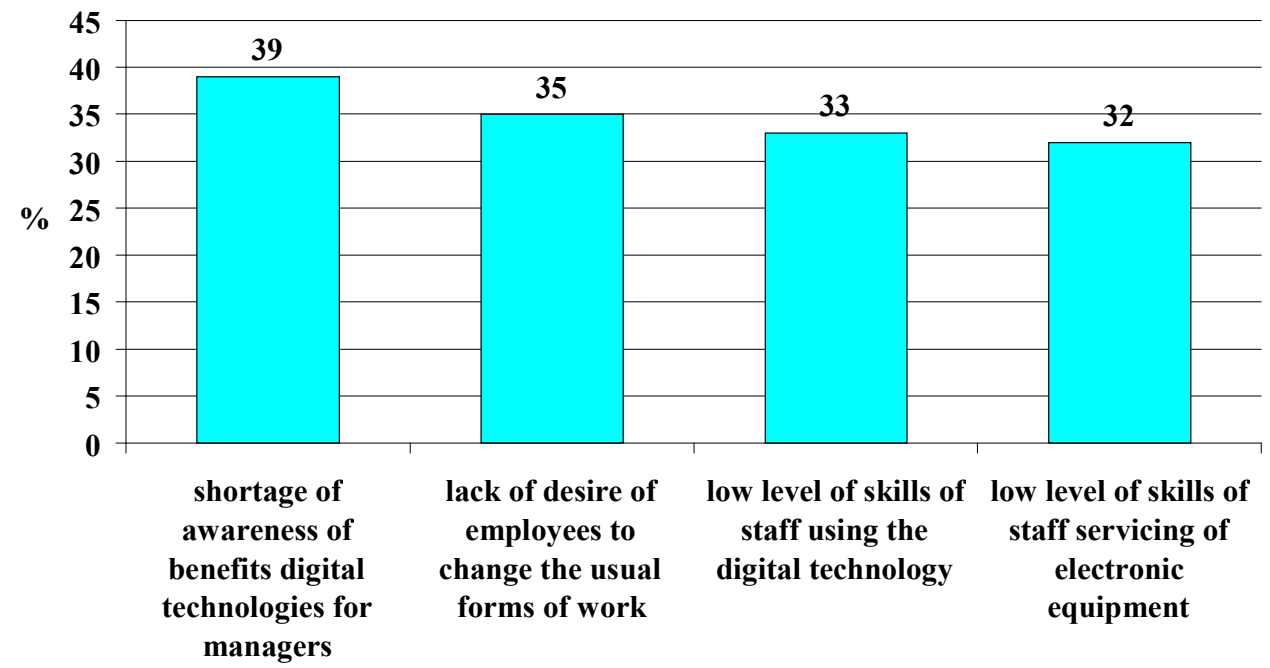

Fig. 3. Barriers to the digitalization of the trade (Source: Rosstat, http://www.gks.ru).

Internal barriers of employee attitudes and their skills indicate the following reasons that interrupt the development of digital technologies in trade:

- shortage of awareness of benefits digital technologies for managers,

- lack of desire of employees to change the usual forms of work,

- low level of skills of staff using the digital technology,

- low level of skills of staff servicing of electronic equipment.

All of these reasons can be reduced to a low level of skills of personnel working with digital equipment.

Figures 4 and 5 show the results of a comparative analysis of the development of digital competencies by students of colleges, technical schools and universities and graduates employed in the specialty (2017 year). 


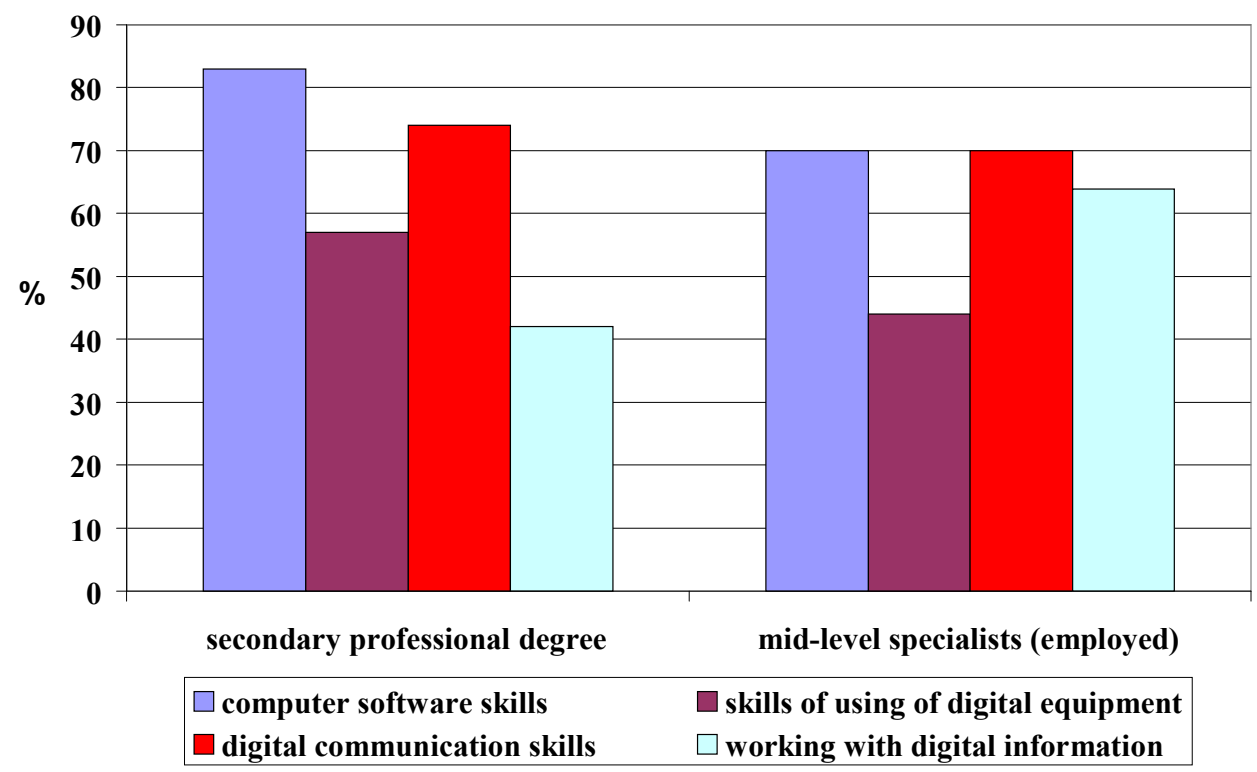

Fig. 4. Digital competencies of secondary professional degree students and mid-level specialists (employed): 2017 (\%) (Source: Education in figures: 2019, Summary of statistics. NRU HSE, 2019, Rosstat, http://www.gks.ru).

A comparative analysis of competencies of secondary school students and employed med-level specialists shows the results:

- college and technical school students have better computer software skills than working high school graduates. The low level of competencies explained by next fact: employed med-level specialists do not create of software in professional activities. This is done by specialists with higher education;

- college and technical school students use of digital equipment better than employed medlevel specialists. Employed med-level specialists use only one type of equipment for working every day. Their professional responsibilities do not involve working with various types of digital equipment;

- employed med-level specialists are better able to cope with the diversity of digital information than students. This fact is explained by their professional responsibilities. Students are less oriented in a variety of digital information. 


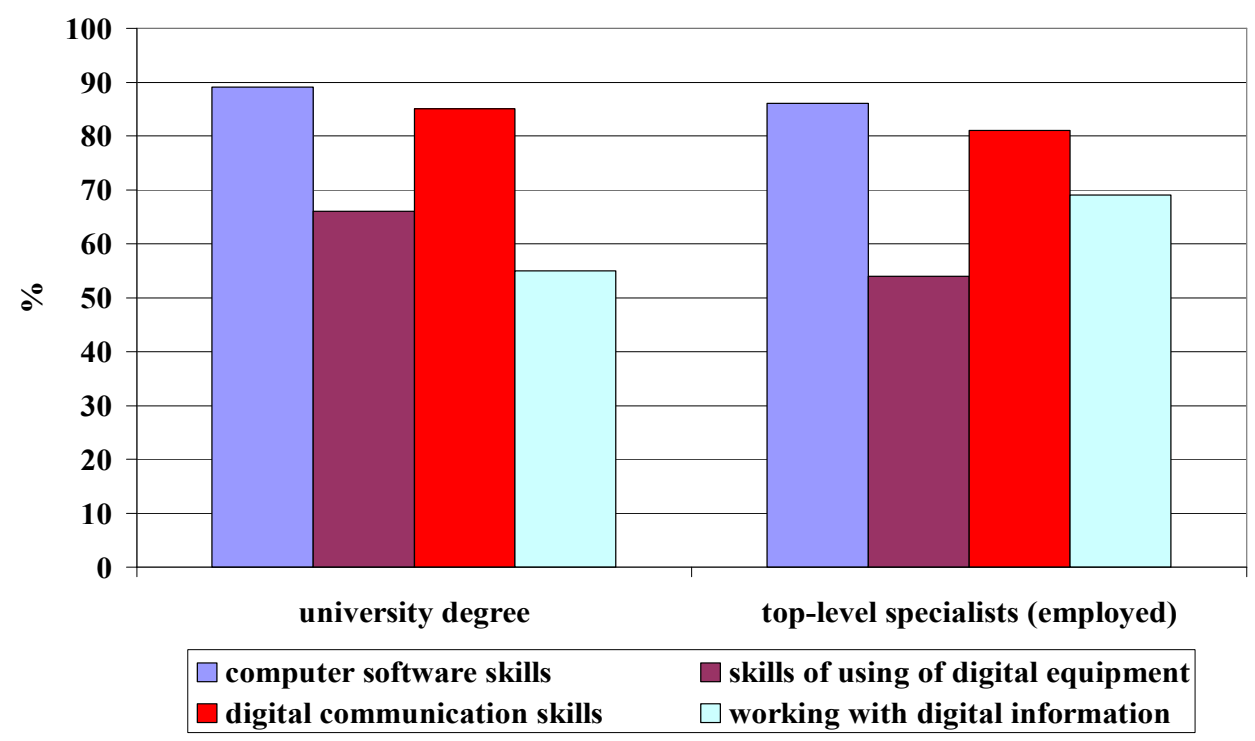

Fig. 5. Digital competencies of university degree students and top-level specialists (employed): 2017 (\%) (Source: Education in figures: 2019, Summary of statistics. NRU HSE, 2019, Rosstat, http://www.gks.ru).

A comparative analysis of competencies of university students and employed top-level specialists shows the results:

- university students and employed top-level specialists have equally well-developed computer software skills. This is because their educational interests are similar and related to the using or creation of software;

- college and technical school students and university students use digital equipment better than employed specialists. The variety of digital equipment is more interesting for students than for workers. Professional responsibilities of working specialists involve working with one type of equipment;

- employed top-level specialists are better at analyzing and summarizing a variety of digital information than students. This fact is explained by their professional responsibilities. Students are focused on studying a specific scientific field and can not synthesize multidirectional information, this is not used in the learning process. Professional activity of a high-level specialists increases the skills of working with a variety digital information. 


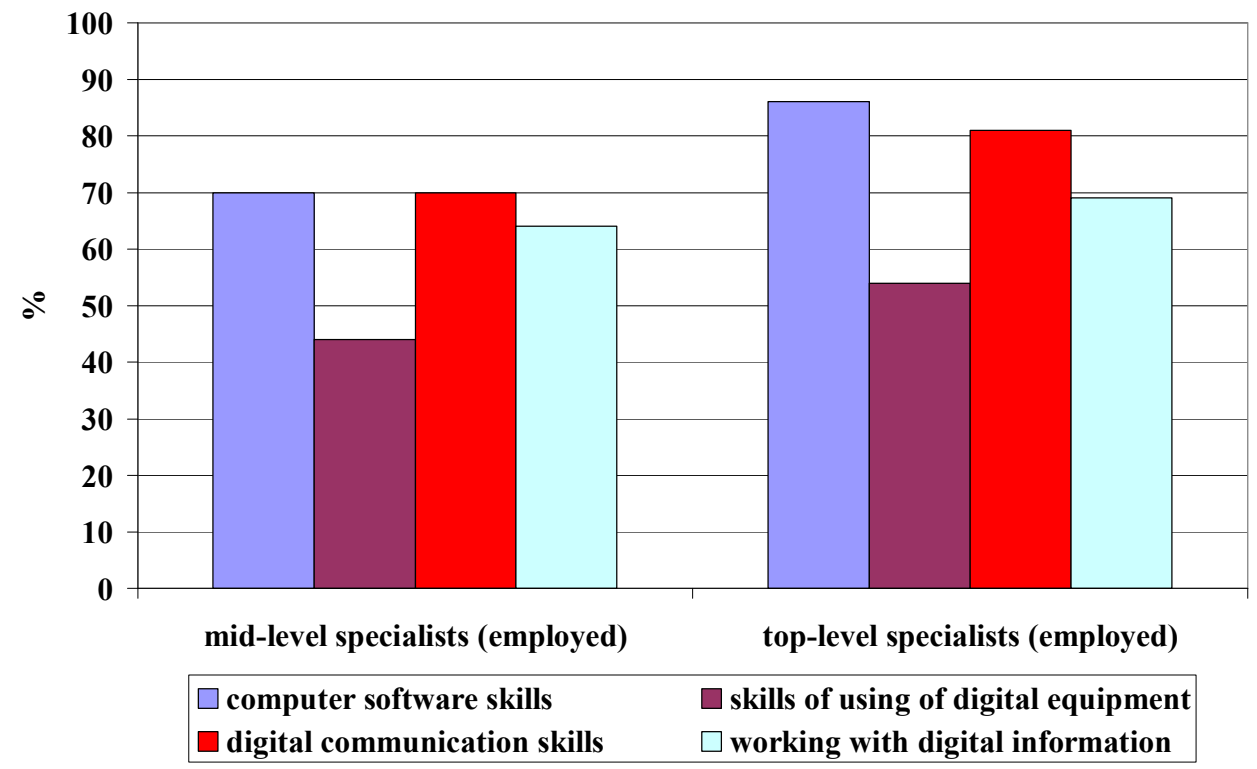

Fig. 6. Digital competencies of mid-level specialists (employed) and top-level specialists (employed): 2017 (\%) (Source: Education in figures: 2019, Summary of statistics. NRU HSE, 2019, Rosstat, http://www.gks.ru).

Figure 6 shows the results of comparing the competencies of employed med-level specialists and employed top-level specialists. Everyone has a less-developed competence of working with digital equipment. But employed top-level specialists have competence for working with digital information a less-developed in the group of digital competencies.

Comparative analysis of the results allows us to draw conclusions:

- training of college and technical school students and university students has the same problems: students have problems in developed skills of working with a variety digital information. Difficulties in integrating heterogeneous digital information are related to the low level of skills of working in conditions of lack of time and responsibility for the consequences of their activities;

- employed graduates have problems of using of digital equipment. The variety of digital equipment is more interesting for students than for employed graduates. Professional responsibilities of employed graduates involve working with only one type of equipment;

- employed university graduates have more problems with digital information compared to employed college and technical school graduates.

\section{Conclusion}

Changes in professional training in the field of trade are related to the processes of digitalization. Using of complex information systems, the requirements for working and technical professions in trade are increasing. Mid-level specialists and skilled workers should understand the functions of digital equipment used in trade processes. The number of employees who are able to perform such work at a high level is not replenished with new personnel, since educational institutions practically do not train middle-level specialists and workers in the necessary areas.

Training specialists for the trade should take into account the specifics of this field of activity and the requirements for working skills in the digital environment $[15,16]$. 
Employees of all levels must have strong digital competencies combined with professional knowledge in trade:

- technological mobility of professional skills that allows to transfer them into different directions;

- specialization in information technology for a specific trade area;

- the ability to transform digital information in accordance with new tasks and the new information;

- integration of digital communicative and creative competencies, which increase the labor potential.

Education of professionals with digital skills for trade should include:

- expand the areas of professional training of information technologies for trade enterprises;

- training in the using of digital technologies must be combined with a practical specialization in trade;

- training in digital technologies in a broad sense should be combined with the specific of trade;

- increase the number of professional secondary schools in popular areas of training for trade enterprises.

Professional education should expand the areas of training in accordance with the requirements of digitalization of modern trade and qualitative changes in the content of work of employees in this field.

\section{References}

1. H. Afonso, D. Holland, J. Pol. Mod. 40(3), 601-613 (2018). https://doi.org/10.1016/j.jpolmod.2018.03.010

2. P.Verhoef, Th. Broekhuizen, Y.Bart, A. Bhattacharya, J.Q. Dong, N. Fabian, M. Haenlein, Journal of Business Research (2019). https://doi.org/10.1016/j.jbusres.2019.09.022

3. N. Leea, St. Clarkeb, Research Policy journal (2016), https://doi.org/10.1016/j.respol.2019.05.012

4. G. E. Alessandro, M. G. Passiante, Technological Forecasting and Social Change 150, 119791 (2020). https://doi.org/10.1016/j.techfore.2019.119791

5. L. Pushkareva, M. Pushkarev. E3S Web of Conferences 135, 04070 (2019). https://doi.org/10.1051/e3sconf/201913504070

6. T. Gorokhova, L. Pushkareva, M. Sredin, M. Pushkarev. E3S Web of Conferences 135, 04069 (2019). https://doi.org/10.1051/e3sconf/201913504069

7. L. G. Hammershoj, Technology in Society 59, 101142 (2019). https://doi.org/10.1016/j.techsoc.2019.05.006

8. K. Dengler, B. Matthes, Technological Forecasting and Social Change 137, 304-316 (2018). https://doi.org/10.1016/j.techfore.2018.09.024

9. E. Titan, A. Burciu, D. Manea, A. Ardelean, Procedia Economics and Finance 10, 269-274 (2014), https://doi.org/10.1016/S2212-5671(14)00302-5

10. L. Desfonteines, E. Korchagina, A.Varnaev, J. Semenova, Proceeding of the $2 d$ International Scientific Conference on Digital Transformation on Manufacturing, Infrastructure and Service (DTMIS). IOP Conf. Ser. Mater. Sci. Eng. 497(1), 012117 (2019). https://doi.org/10.1088/1757-899X/497/1/012117 
11. L. Desfonteines, E. Korchagina, Proceedings of the 33rd International Business Information Management Association Conference, IBIMA: Education Excellence and Innovation Management through Vision 2020, 2216-2221 (2019).

12. I. Krasyuk, T. Kirillova, S.Sergeev, E3S Web of Conferences 91 (2019). https://doi.org/10.1051/e3sconf/20199105007

13. I. Krasyuk, A. Kobeleva, P. Mikhailushkin, G. Terskay, A. Chuvakhina, Espacios 39 (31) (2018)

14. E. Korchagina, O. Shvetsova, Proceedings of 2018 17th Russian Scientific and Practical Conference on Planning and Teaching Engineering Staff for the Industrial and Economic Complex of the Region, PTES, 138-140 (2018).

15. I. Asfondiarova, V. Demchenko, K. Illarionova, E. Kravtsova, Proceeding of the $2 d$ International Scientific Conference on Digital Transformation on Manufacturing, Infrastructure and Service (DTMIS-2018). IOP Conf. Series.: Materials Science and Engineering 497, 012106 (2019). https://doi.org/10.1088/1757-899X/497/1/012106

16. K. Illarionova, S. Grigoryev, I. Asfondiarova, Proceeding of the $2 d$ International Scientific Conference on Digital Transformation on Manufacturing, Infrastructure and Service (DTMIS-2018). IOP Conf. Series.: Materials Science and Engineering 497, 012110 (2019), https://doi.org/10.1088 / 1757-899X / 497/1/012110 